\title{
Article \\ Physical Investigation of Deformation Behaviour of Single and Twin Tunnel under Static Loading Condition
}

\author{
Parvesh Kumar *(D) and Amit Kumar Shrivastava (D) \\ Department of Civil Engineering, Delhi Technological University, Delhi 110042, India; aksrivastava@dce.ac.in \\ * Correspondence: parveshkumar_2k16phdce06@dtu.ac.in
}

Citation: Kumar, P.; Shrivastava,

A.K. Physical Investigation of

Deformation Behaviour of Single and Twin Tunnel under Static Loading Condition. Appl. Sci. 2021, 11, 11506. https://doi.org/10.3390/app 112311506

Academic Editor: Chin Leo

Received: 11 September 2021

Accepted: 24 November 2021

Published: 4 December 2021

Publisher's Note: MDPI stays neutral with regard to jurisdictional claims in published maps and institutional affiliations.

Copyright: (c) 2021 by the authors. Licensee MDPI, Basel, Switzerland. This article is an open access article distributed under the terms and conditions of the Creative Commons Attribution (CC BY) license (https:// creativecommons.org/licenses/by/ $4.0 /)$.

\begin{abstract}
This paper presents a new testing method for the problems encountered in field testing. To this end, single-tunnel and twin-tunnel small-scale rock models are prepared in the laboratory. A new methodology is proposed to encounter problems that are faced during field testing. The test results show that rock strength characteristics, overburden pressure, and tunnel spacing have important effects on the stability of underground structures. For rocks with poor strength properties, the damage degree is greater. When the strength property of rock changes, the deformation value of unlined tunnels changes from $21.05 \%$ to $27.58 \%$, while that of lined tunnels changes from $11 \%$ to $21.42 \%$. Also, in the twin tunnel, the deformation value reduces from $20 \%$ to $15.78 \%$ when the spacing between the tunnels is increased. For the measurement of stress and deformation in tunnels, the results obtained from experiments are analyzed. The method adopted in this study helps determine the tunnel's design parameters to make it safe under overlying static loads. Finally, the key factors affecting the stability of underground structures are determined by simulating the field conditions through experimental research.
\end{abstract}

Keywords: underground structures; static loading; geo-material; lined tunnels; twin-tunnel; physical modelling

\section{Introduction}

Excessive deformation in shallow-depth underground structures has always posed a danger to infrastructure safety during the construction of tunnels, particularly when the tunnel crosses a highly stressed induced area, especially in metropolitan areas and mountainous terrain. Hence, the main purpose of structure design is to reduce deformations by reducing stress in the rock mass. In the excavation of underground structures, the problem of stress concentration is resolved by developing a stress field that is distributed as equally as possible. As a result, the best support systems can be given without compromising the structure's protection. The stability of underground structures is influenced by various factors such as overburden pressure, in-situ stresses, engineering properties of the rock, and static and dynamic loading conditions. At shallow depths, a tunnel in a weak rock mass is extremely vulnerable to disruption. Mechanical properties, e.g., unconfined compressive strength, tensile strength, and modulus of elasticity of the surrounding rock mass, deteriorate under the impact of disruption and consistent deformation. If a tunnel is constantly subjected to high-stress conditions, after a certain time, the engineering and geological properties of rock may collapse. Therefore, the main aim of design engineers is to minimize the effect of deterioration and keep the structure protected from the stresses that have formed along with its crown, sidewalls, and bottom surfaces during the construction of tunnels. Static loading conditions mainly arise because of overlying rock or soil strata. Almost all underground structures involve excavation or digging, and the soil or rock mass in this process issubjected to initial loads. As a result, the surrounding soil or rock mass, along with underground structures, is subjected to static load. Therefore, it is vital to understand how underground systems behave under 
different loading conditions.In the case of twin tunnels, there is a significant effect of the construction method and position of tunnels on their settlement behaviour [1,2]. The stability behaviour of brick-lined tunnels under extreme loading was investigated, and results showed that brick-lined tunnels show more brittle behaviour when subjected to concentrated loading conditions [3]. The deformation obtained in the tunnel lining in the clayey medium in the vertical direction is greater than the horizontal displacement [4]. The effect of deconfinement methods on the behaviour of the tunnel is explained [5]. In the case of a twin tunnel, the lagging distance affects the surface settlement behaviour of the tunnel [6]. The construction of a new tunnel significantly affects the settlement behaviour of the existing tunnel [7-10]. The behaviour of different types of sections of the twin tunnel was investigated and it was found that circular tunnels are the best among all types of tunnel sections [11]. In the case of two crossing tunnels, the surface settlement caused due to excavation is greater when the second tunnel is excavated above the first tunnel [12]. The settlement induced in shield tunnelling is influenced by various factors such as the geological state of the region which is to be excavated, the load acting on the ground surface, methods of construction, and reinforced and unreinforced tunnel faces [13-15]. The effect of stiffness ratio, the soil layer thickness lying above the tunnel, and the cohesion properties of soil has a significant effect on the stresses acting on tunnels $[16,17]$. The effect on the deformation behaviour of a tunnel excavated in soil medium when subjected to internal blast loading wasstudied, and it was found that the failure in the tunnel lining mainly depends upon the different quantities of explosive [18]. The dip angle of the joint in the case of a tunnel having jointed rock mass plays an important role in the stability analysis of the tunnel [19-22]. The most critical section of the tunnel which experienced the maximum deformation is the top surface of the tunnel, i.e., the crown of the tunnel. The circular tunnel section experienced the maximum deformation compared to the horseshoe section [23]. A numerical study was conducted to determine the deformation effect in the case of cut and cover tunnel structures under the effect of dynamic loading [24]. The roof and floor of the tunnel experience the maximum deformation in the case of blast loading $[25,26]$. The rock sample in the case of coupled static and dynamic loading experienced tensile failure [27]. In the case of a twin tunnel, the tunnel stability mainly depends upon the spacing and the diameter of the tunnel $[28,29]$. The effect of displacement, yield zone, and stresses on underground structures was investigated both experimentally and with numerical modelling, and it was found that the horizontal displacement for the two methods was quite similar, but the vertical displacement in the numerical simulation was slightly less than the physical model test result [30]. The elastic modulus of the ground has a significant effect on the settlement of the tunnel structures [31]. Various factors such as clearance distance, advancing distance, and influence of multiple new tunnels significantly affect the stability behaviour of the existing tunnel [32]. The value of deformation in the existing tunnel changes when a new tunnel is excavated nearby [33]. A parametric study on the lined and unlined tunnel at shallow depth under coupled static and cyclic loading showed that the strain in the lined tunnel is less than the strain in the unlined tunnel because of the resistance offered by the tunnel lining [34]. The deformation of tunnels at a shallow depth subjected under static and dynamic loading conditions mainly depends upon the strength characteristics of rock $[35,36]$. With an increase in spacing between the tunnels, the settlement reduces [37-39]. The interaction behaviour between the twin tunnel and underground parking wasstudied, and the result showed a significant effect of the construction procedure of the tunnel on its stability behaviour [40,41]. In the case of the dynamic behaviour of double-lined shield tunnels under impact loading, with an increase in the impact velocity and impact angle, there is an increase in the dynamic response of the tunnel [42]. Modelling rock masses with joints that are fixed with the help of rock bolts in the construction of the tunnel was studied, and it was concluded that the modelling of rock bolts and jointed rock masses should be done at the same time [43]. A study on twin tunnels at shallow depth using FE analysis showed that as the spacing between the tunnel decreases, the interaction effect increases [44]. The creep behaviour of clay and the 
cohesion of soil play an important role in the deformation behavior of shallow tunnels in clayey medium [45-48]. A study conducted on twin tunnels under dynamic and static loading conditions using UDEC software showedthat twin tunnels are very unstable under both loading conditions. In the case of static loading, the displacement along the crown of the tunnel is very large as compared to the rest of the tunnel section [49]. The presence of asperity also affectsthe shear behaviour of rock joints [50]. The shear behaviour of infilled rock joints is dependent upon the thickness of the infill material [51,52]. The dynamic behaviour of the tunnel under blast loading shows that the deformation in the tunnel mainly depends upon the rock type and the weathering of the rock [53]. The experimental and numerical analysis of the deformation behaviour of a tunnel excavated in weak rock showed that the shear strain acting on the tunnel's periphery developedacrack around the tunnel [54]. The effect of principal stress orientation on the stability of a regular tunnel and cracked tunnel was investigated, and it was found that the critical compressive stress varies with the angle of inclination of the crack [55]. With an increase in the spacing between the tunnels when they are closely spaced, the ground loss percentages caused by the second tunnel decreases [56]. The dynamic stresses induced during earthquakes along the face of the tunnel increase the chances of settlement along the tunnel axis and the effect of deformation is greater in the case of an unreinforced tunnel section [57].

\section{Problem Statement}

In the present study, single and twin tunnels excavated at shallow depth in metro cities are included. In the National Capital Territory of Delhi, the depth of metro tunnels varies from 0 to $30 \mathrm{~m}$. These tunnels are constructed underground as well as overhead in some places, depending upon the technical feasibility and availability of space. Therefore the variation from overhead to underground represents the change in the cover depth. The main objective of the present study is to access the stability behaviour of single and twin tunnels when subjected to static loading conditions. To achieve this, various models of single and twin tunnels were casted in laboratory. The study was conducted on various parameters of single and twin tunnels. The results obtained from the experimental testing were analyzed. In previous studies, much work has been done by analytical and numerical modelling, whereas there is less deformation assessment of single and twin tunnels using experimental modelling. In the present study, deformation assessment of tunnels is done with the help of LVDTs, which are used to compute the deformation in the tunnel, which is seen very little in the previous studies. Therefore the new methodology proposed in the present study is beneficial for deciding the various tunnel parameters for the safe and economical design of the tunnel.

\section{Selection of Model Material}

For the present study, three different geo-materials were selected to prepare the rock tunnel models: POP (Plaster of Paris), GM1, and GM2. These three geo-materials were selected to vary the strength properties of the rock as they mixed in different proportions. The purpose of mixing these geo-materials in different proportions was to vary the strength parameter of the rock. The model materials were selected according to their stress-strain behaviour. To prepare the tunnel models, Plaster of Paris, Kalonite clay, and sand were used in different proportionsas shown in Table 1. Plaster of Paris is an easily available material, and it can be moulded into any shape. The Kalonite clay used in this study was characterized in the laboratory, and its basic engineering properties were determined. The unconfined compressive strength and the dry density of the Kaolinite clay were determined as per IS 2720 (Part-10), 1991, and IS 2720 (Part-7), 1980 and found to be $8.7 \mathrm{KPa}$ and $13.5 \mathrm{KN} / \mathrm{m}^{3}$, respectively, whereas the value of liquid limit and the plastic limit were determined to be $56 \%$ and $28 \%$ respectively, as per IS 2720 (Part-5), 1985. To classify the sand type, grain size analysis was carried out, and the fineness modulus of the sand was determined as 2.754 as per IS: 2386 (Part I)-1963, which means the sand is classified as medium sand. These three materials were mixed in different proportions to 
make a synthetic material. In the case of the twin tunnel sample, only Plaster of Paris material was used as model material, and the water powder ratio is kept at 0.6 in all types of compositions.

Table 1. Composition of the Synthetic Material used for making single tunnel models.

\begin{tabular}{ccccc}
\hline Synthetic Material & POP & Sand & Clay & Water Content \\
\hline POP & $100 \%$ & - & - & $60 \%$ \\
GM-1 & $50 \%$ & $40 \%$ & $10 \%$ & $60 \%$ \\
GM-2 & $50 \%$ & $30 \%$ & $20 \%$ & $60 \%$ \\
\hline
\end{tabular}

\subsection{Fixing Dimension of Tunnel Models}

The geometry of both single and twin tunnel models were decided according to the boundary conditions. The dimension of the single tunnel model was $30 \mathrm{~cm} \times 25 \mathrm{~cm} \times 23 \mathrm{~cm}$ $(\mathrm{L} \times \mathrm{W} \times \mathrm{H})$. The cover depth of the tunnel wasdecided to be $3 \mathrm{~cm}$ and $5 \mathrm{~cm}$. The tunnel diameter was $5 \mathrm{~cm}$ in all cases, which was decided according to the ease of workability. The width of the tunnel sample was $250 \mathrm{~mm}(\mathrm{r}=4 \mathrm{a}$, where " $\mathrm{a}$ " is the radius of the tunnel and " $r$ " is the radial distance). For lined samples, PVC pipe was used as a liner material. The thickness of the PVC pipe was $1.74 \mathrm{~mm}$, and its length was $30 \mathrm{~cm}$, i.e., the length of the tunnel sample. The dimension of the twin tunnel sample was $42.5 \mathrm{~cm} \times 37.5 \mathrm{~cm} \times 23 \mathrm{~cm}$ $(\mathrm{L} \times \mathrm{W} \times \mathrm{H})$. The width of the twin tunnel was decided according to the boundary conditions (i.e., $r=4 a$, where " $a$ " is the radius of the tunnel. Twin tunnel samples were tested for three different spacings, i.e., 1.5D, 2D, and 2.5D (where ' $\mathrm{D}$ ' is the tunnel's diameter). The cover depth of the tunnel was $3 \mathrm{~cm}$ and $5 \mathrm{~cm}$ from the top of the model surface. The tunnel diameter was $5 \mathrm{~cm}$, the same as in the case of the single tunnel sample. In the case of twin tunnel models, again PVC pipe was used as a liner material in the case of lined tunnels. Both lined and unlined samples of twin tunnels were prepared in the laboratory.The tunnel model diagram is shown in Figure 1.
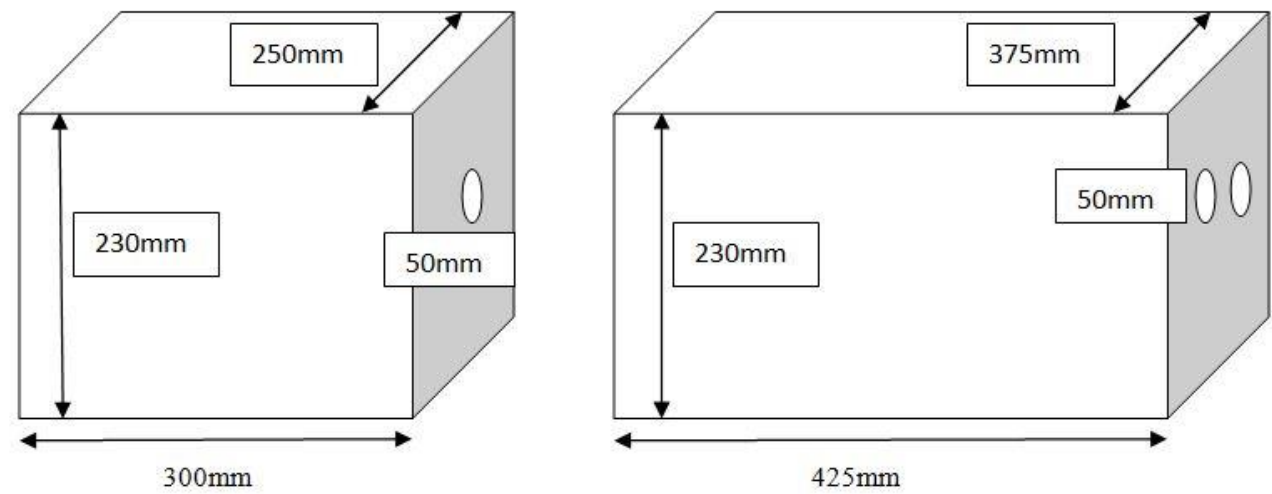

Figure 1. Tunnel model diagram for Single Tunnel and Twin Tunnel.

\subsection{Preparation of Sample}

To determine the engineering properties of the model materials, cylindrical samples of diameter $38 \mathrm{~mm}$ and length $76 \mathrm{~mm}$ were prepared. The water content was kept at $60 \%$ for all 3 model materials. Figure 2 shows the failure samples of GM1 and GM2 material after the UCS test and 3 different materials prepared for the Brazilian test to determine the indirect tensile strength. 

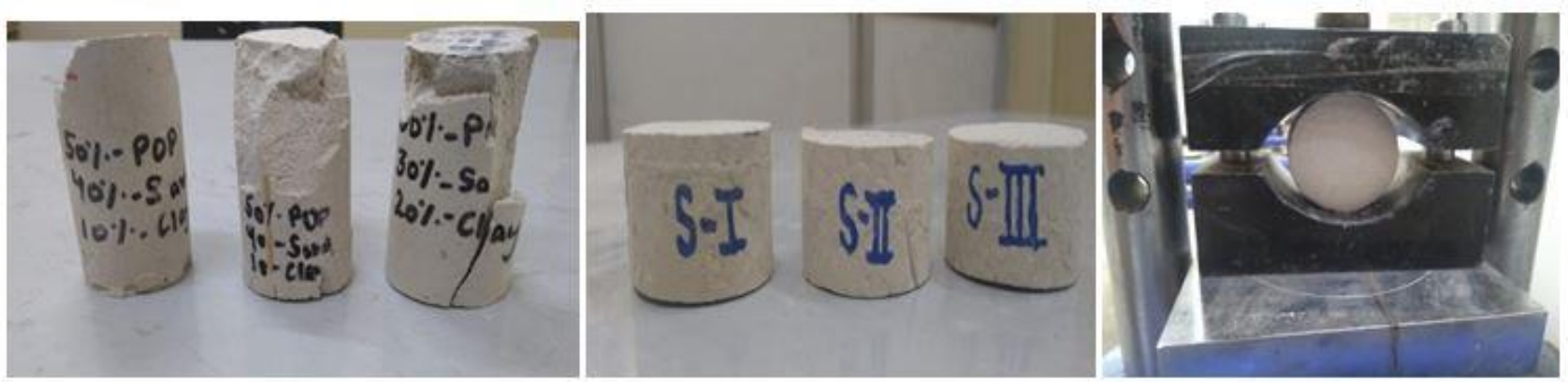

Figure 2. Tested UCS specimen and prepared samples for Brazilian tests.

After selecting the composition of the model material, the engineering properties of the model material were determined. Various cylindrical samples of diameter $38 \mathrm{~mm}$ and length $76 \mathrm{~mm}$ were casted in the laboratory, and these samples were tested to determine the engineering properties. The average value of dry density of the Plaster of Paris (POP) material sample was found to be $12.10 \mathrm{KN} / \mathrm{m}^{3}$ whereas, for GM- 1 and GM- 2 material, the average value of dry density was found to be $10.8 \mathrm{KN} / \mathrm{m}^{3}$ and $10.1 \mathrm{KN} / \mathrm{m}^{3}$, respectively. The average uniaxial compressive strength of Plaster of Paris material was found to be 10.5 MPa. Similarly, for GM-1 and GM-2 materials, various samples were cast, and it was found that the average uniaxial compressive strength of GM1 and GM2 materials were 7.4 MPa and 5.7 MPa, respectively. Various tests were conducted to determine the indirect tensile strength of the model materials. It was found that the average value of tensile strength for Plaster of Paris material was $0.78 \mathrm{MPa}$, whereas, for GM-1 and GM-2, the average value was found to be $0.56 \mathrm{MPa}$ and $0.38 \mathrm{Mpa}$, respectively. The average value of Young's Modulus for Plaster of Paris material was found to be $2500 \mathrm{MPa}$, whereas, for GM-1 and GM-2, the average value of Young's modulus was found to be $1890 \mathrm{MPa}$ and $1650 \mathrm{MPa}$. The average value of Young's Modulus for lining material was found to be $4900 \mathrm{MPa}$. According to Deere Miller classification (1968), the classification of POP, GM-1, and GM-2 was done as EM (Medium Elastic). As the unconfined confined strength of all the all the three model materials was greater than $1 \mathrm{MPa}$ which means that they represent a rock structure. Therefore, the structure of rock mass can be simulated with the actual tunnel engineering structure excavated in weak rock. The engineering properties of the model material were determined according to the standard procedure for the rock mechanics laboratory. The different engineering properties of all three model materials are discussed below in Table 2.

Table 2. Parameters determined for different Geo-materials.

\begin{tabular}{ccccc}
\hline Properties & POP & GM-1 & GM-2 & Testing Method \\
\hline Dry Density $\left(\mathrm{KN} / \mathrm{m}^{3}\right)$ & 12.10 & 10.8 & 10.1 & ISRM (1977) \\
Specific Gravity, G & 2.65 & 2.42 & 2.22 & IS (4031, 1995) \\
UCS (MPa) & 10.5 & 7.4 & 5.7 & ISRM (1979) \\
Tensile Strength $(\mathrm{MPa})$ & 0.78 & 0.56 & 0.38 & IS:10082 (1981) \\
Modulus E E $(\mathrm{MPa})$ & 2500 & 1890 & 1650 & ISRM (1979) \\
Poission Ratio & 0.23 & 0.18 & 0.15 & ISRM (1979) \\
Deere-Miller Classification & EM & EM & EM & \\
\hline
\end{tabular}

\subsection{Testing Equipment}

A compression testing machine of capacity $2000 \mathrm{KN}$ was used for testing single and twin tunnel samples of weak rock under static loading conditions. The apparatus mainly consists of a loading unit, data acquisition system, and LVDT for displacement measurement. The loading unit consists of $50 \mathrm{~cm} \times 50 \mathrm{~cm}$ platen on which the tunnel sample is placed. The thickness of the platen is $5 \mathrm{~cm}$. The vertical clearance between the upper and lower platen is $60 \mathrm{~cm}$. The ramp has a travel capacity of $5 \mathrm{~cm}$ in the upward 
direction. A 16-CH LVDT data acquisition system was attached to the loading unit. LVDTs were fixed along the length of the tunnel in different positions. LVDT is a device that is used to take displacement at any point when the load is applied. The displacement range of LVDT was $\pm 20 \mathrm{~mm}$. Three LVDTs were placed at three different locations inside the tunnel from the bottom of the model. For that, holes were drilled, and LVDT was placed inside these holes. The data logger system was further attached to the CPU via a cable wire. Load and deformation values of the tunnel models were stored as notepad data. With the help of software provided with the LVDT data logger, various graphs between load vs. time, load vs. deformations can be plotted.

In the present study, a Chennani-Nashri tunnel is considered the prototype, from where the properties of rock mass and tunnel lining are chosen to fix the dimension of the model. The ratio of elastic modulus of lining material to the elastic modulus of surrounding rock mass $\left(\mathrm{E}_{\text {lining }} / \mathrm{E}_{\text {rock }}\right)$ is kept fixed for the laboratory models so that they can represent the actual field conditions. The rock mass present in the Chennani-Nashri tunnel consists of sandstone and siltstone. The elastic modulus of sandstone is reported as $15 \mathrm{GPa}$, whereas the shotcreting is done using M30 grade concrete, whose value of elastic modulus is $28 \mathrm{GPa}$.Therefore it is found that the elastic modulus ratio $\left(\mathrm{E}_{\text {lining }} / \mathrm{E}_{\text {rock }}\right)$ is 1.9 for field conditions.

$$
\left(\mathrm{E}_{\text {Lining }} / \mathrm{E}_{\text {Rock }}\right)_{\text {Field }}=\left(\mathrm{E}_{\text {Lining }} / \mathrm{E}_{\text {Rock }}\right)_{\text {Physical Model }}=1.9
$$

\section{Physical Modelling of Single and Twin Tunnel}

Physical modelling is a very useful method to simulate field conditions in the laboratory because, in field conditions, it is not possible to conduct all the tests. In this study, physical modelling of a single tunnel and twin tunnel is done under static loading conditions. The purpose of conducting a physical investigation is to determine the effect of cover depth, strength properties of rock, and spacing between the tunnels on the stability behaviour of tunnels. The effect of the presence of liner material on the deformation of the tunnel is also studied. In the case of the single tunnel, the test has been performed on all three types of material, i.e., Plaster of Paris, GM-1, and GM-2 material. All three model materials are characterized in the earlier stage. More than 36 models of the lined and unlined tunnel are prepared in Perspex moulds. The size of the tunnel model is $30 \mathrm{~cm} \times 25 \mathrm{~cm} \times 23 \mathrm{~cm}$. $(\mathrm{L} \times \mathrm{W} \times \mathrm{H})$. The experimental study is conducted on two different cover depths, i.e., $3 \mathrm{~cm}$ and $5 \mathrm{~cm}$, as discussed earlier. Polyvinyl Chloride pipe is used as a liner material. After the preparation of the models, three LVDTs are fixed along the length of the tunnel. For fixing LVDTs, three different locations are selected to take the deformation in the tunnel. After the marking of locations to fix LVDTs in the model, holes are drilled with the help of a drill machine up to the bottom lining of the tunnel. After drilling holes, three LVDTs are fixed at three different locations, i.e., L/3, L/2 and $7 \mathrm{~L} / 12$,where " $\mathrm{L}$ " is the length of the tunnel model. In single tunnels, the deformation is taken at points $0,10 \mathrm{~cm}, 12 \mathrm{~cm}, 15 \mathrm{~cm}, 18 \mathrm{~cm}, 20 \mathrm{~cm}$, and $30 \mathrm{~cm}$ along the length of the tunnel.After placing the LVDTs, the tunnel model is kept inside the compression testing unit attached with the 16-Ch LVDT data logger. Then the load is applied with the help of a compression testing machine. After the failure of the sample, it is removed from the platen. LVDTs are then removed gently from the tunnel sample. Figure 3 shows the location of points where the deformation is taken in a single and twin tunnel. 
L

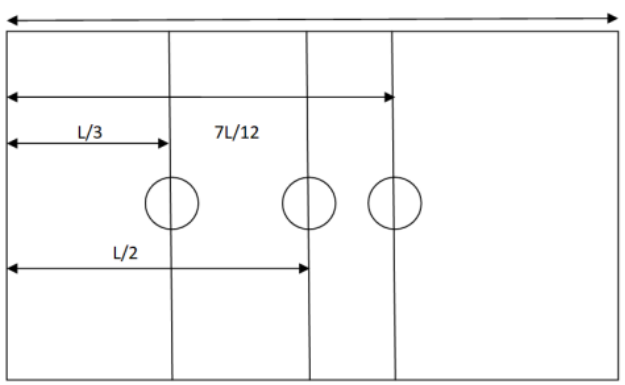

(a)
$\mathrm{L}$

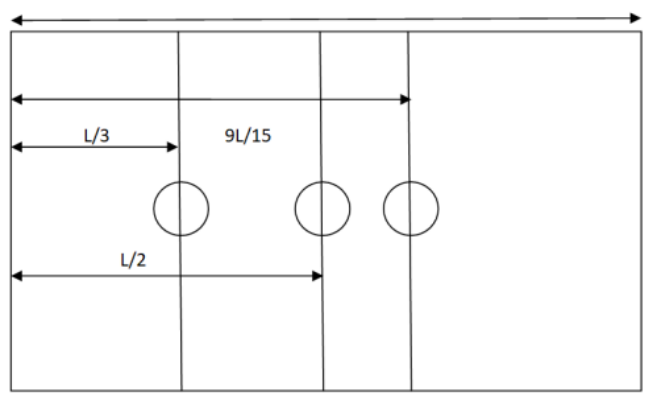

(b)

Figure 3. Location where the deformation is taken in (a) Single tunnel and (b)Twin Tunnel.

In the case of the twin tunnel, the sample is made of $100 \%$ Plaster of Paris material at $60 \%$ water content. The dimension of the twin tunnel sample is $42.5 \mathrm{~cm} \times 37.5 \mathrm{~cm} \times 23 \mathrm{~cm}$ $(\mathrm{L} \times \mathrm{W} \times \mathrm{H})$. Twin tunnel samples are tested for three different spacings, i.e., 1.5D, 2D, and $2.5 \mathrm{D}$ (where ' $\mathrm{D}$ ' is the diameter of the tunnel). The cover depth of the tunnel is $3 \mathrm{~cm}$ and $5 \mathrm{~cm}$ from the top of the model surface. Both lined and unlined samples of twin tunnels are prepared in the laboratory. The steps for the preparation of tunnel models are shown in Figures 4 and 5 and show the single and twin tunnel samples prepared in the laboratory. To take the deformation in the tunnel sample, six LVDTs are placed at different locations. The location of LVDTs in the tunnel sample is chosen according to the extent of deformation that occurs in the tunnel when applied to static loading conditions. Three LVDTs are placed in each tunnel at three different locations. LVDTs are placed at a distance $\mathrm{L} / 3, \mathrm{~L} / 2$, and 9L/15, where ' $\mathrm{L}$ ' is the length of the tunnel. In twin tunnels, the deformation is taken at points $0,14.1 \mathrm{~cm}, 17 \mathrm{~cm}, 21.25 \mathrm{~cm}, 25.5 \mathrm{~cm}, 28.4 \mathrm{~cm}$, and $42.5 \mathrm{~cm}$ along the length of the tunnel.To place the LVDTs, the same method as adopted in a single tunnel is followed. For installation, 6 holes of $10 \mathrm{~mm}$ diameter are drilled from the bottom of the surface, as shown in Figure 6. The LVDT is fixed with the help of a three-pin clamp to keep it tight so that it does not move from its location. After fixing the LVDTs in the single and twin tunnel samples, the samples are placed in a compression testing machine under the effect of static loading. The load is then applied to the sample, as shown in Figure 7. The loading rate is $1 \mathrm{Kn} / \mathrm{s}$ so that the load acts gradually on the tunnel sample.

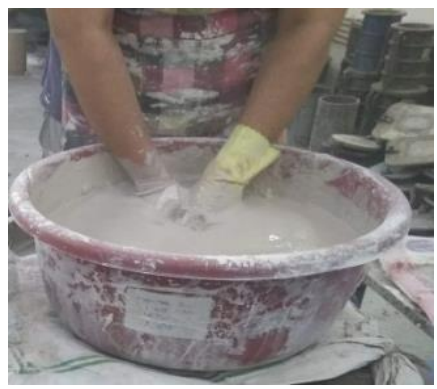

(a)

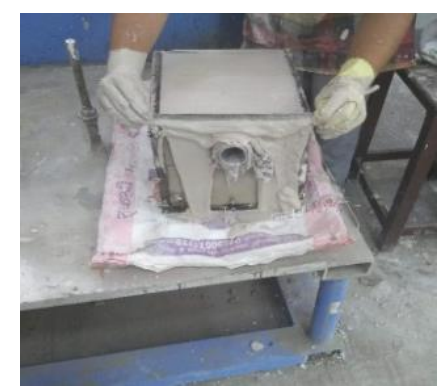

(b)

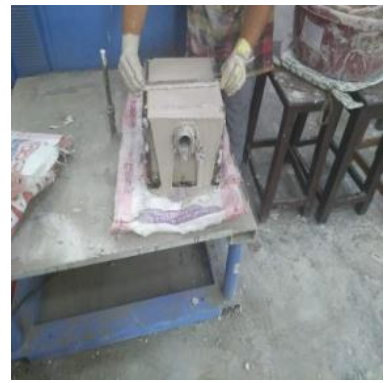

(c)

Figure 4. Steps for preparation of tunnel samples (a) Mixing (b) Vibrating (c) Leveling surface. 


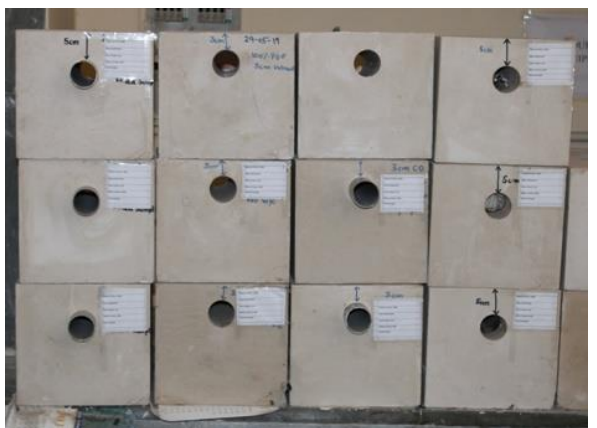

(a)

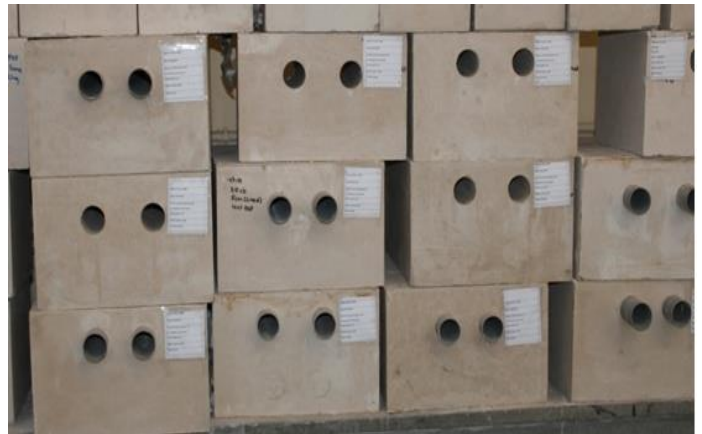

(b)

Figure 5. Prepared samples of (a) Single tunnel and (b)Twin Tunnel.

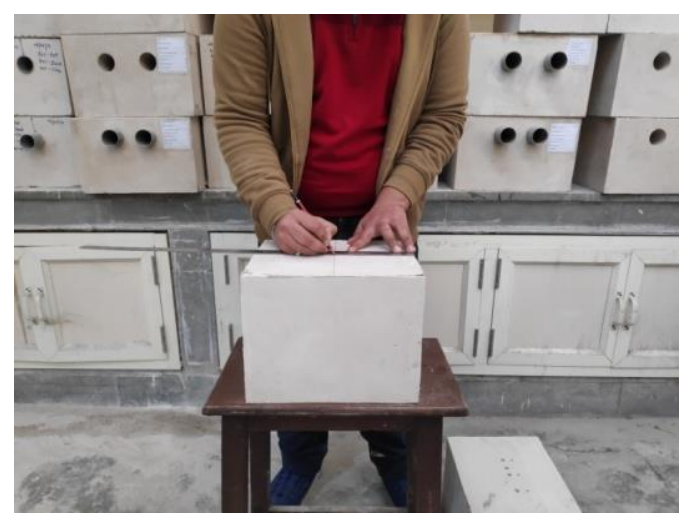

(a)

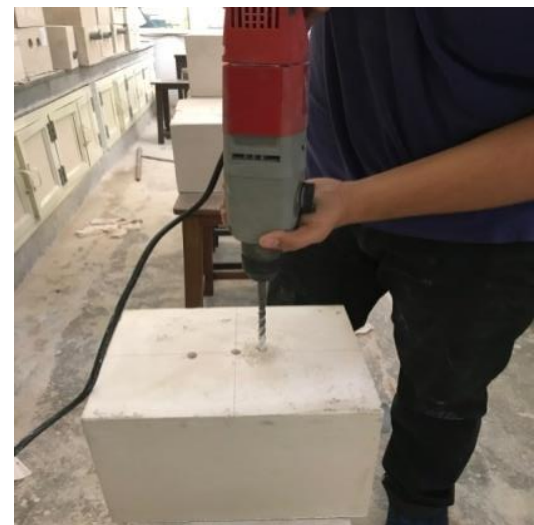

(b)

Figure 6. (a) Marking the dimensions and (b) Drilling the sample.

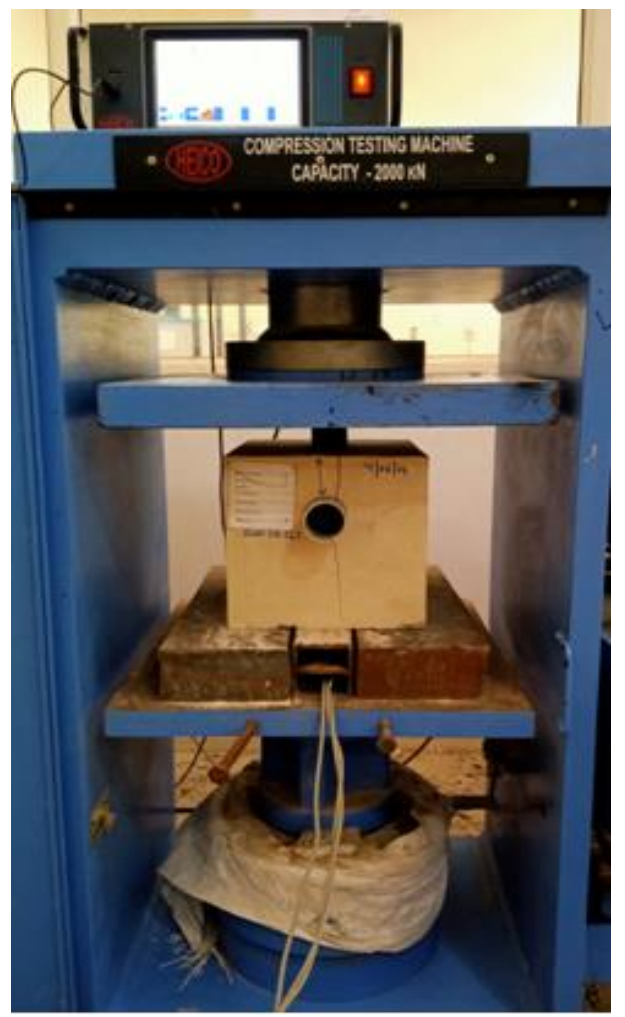

Figure 7. Single tunnel model subjected to loading conditions. 


\section{Results and Discussion}

\subsection{Deformation Behaviour of Single Tunnels}

After conducting the test on both lined and unlined tunnels, the results are analyzed. It has been noted that deformation is more in unlined samples as compared to lined samples. This is due to the absence of liner material in the unlined tunnel, as the liner material offers resistance against the developed stresses. It is also reported that the strength properties of the rock and cover depth also play an important role in the deformation behaviour of tunnels. GM-1 and GM-2 models experience more deformation as compared to POP models; this is due to their weak strength characteristics. From the results, it can also be concluded that the maximum deformation is experienced at the centre of the tunnel, i.e., $\mathrm{L} / 2$, as compared to the LVDTs fixed at $\mathrm{L} / 3$ and $7 \mathrm{~L} / 12$. It is also observed that as the distance from the centre of the tunnel increases towards the end faces of the tunnel, the effect of deformation decreases. No deformation is experienced at the end of the tunnel in all cases.

Firstly, the single tunnel models prepared from 100\% POP material are tested with a compression testing machine. As the load is applied to the top surface of the tunnel sample, it begins to deform. Then, the deformation is observed at various selected points along the tunnel length. For the sample prepared from 100\% Plaster of Paris material, the deformation graph is shown in Figure 8. The deformation value obtained from the graph shows that maximum deformation is experienced in unlined samples having less cover depth, i.e., in the case of a $3 \mathrm{~cm}$ unlined tunnel which is quite obvious because liner material is absent in unlined samples. The centre location of the tunnel, i.e., L/2,experienced the maximum deformation in the case of $3 \mathrm{~cm}$ cover depth. Less deformation is computed at $\mathrm{L} / 3$ and $7 \mathrm{~L} / 12$ distances. In the case of $3 \mathrm{~cm}$ cover depth unlined samples, the maximum crown deformation experienced at $\mathrm{L} / 2$ distance is $0.19 \mathrm{~mm}$, whereas the deformation noticed at points $\mathrm{L} / 3$ and $7 \mathrm{~L} / 12$ is $0.03 \mathrm{~mm}$ and $0.13 \mathrm{~mm}$. In the case of $5 \mathrm{~cm}$ unlined tunnels, the crown deformation at $\mathrm{L} / 2$ distance is $0.16 \mathrm{~mm}$. The minimum deformation is noticed in the case of a $5 \mathrm{~cm}$ lined sample. This is due to the presence of liner material. In the case of $5 \mathrm{~cm}$ lined samples, the deformation experienced at $\mathrm{L} / 3, \mathrm{~L} / 2$, and $7 \mathrm{~L} / 12$ is $0.01 \mathrm{~mm}, 0.08 \mathrm{~mm}, 0.03 \mathrm{~mm}$, respectively.

\section{Distance along the Tunnel Length $(\mathrm{cm})$}

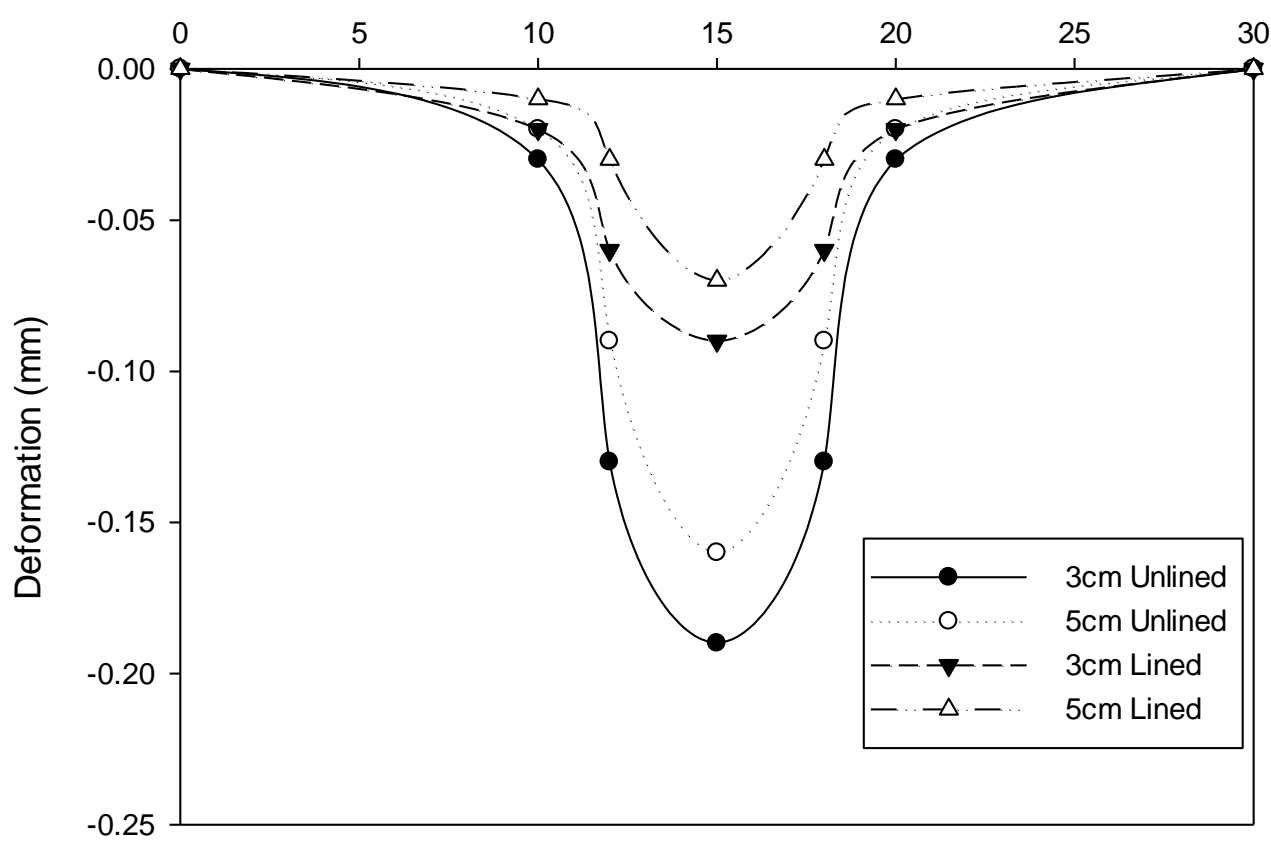

Figure 8. Deformation Profile of Lined and Unlined Tunnel for 100\% POP material. 
Secondly, the tunnel samples of GM-1 material (50\% POP, 40\% Sand, and 10\% Clay) are tested with a compression testing machine, and the deformation graph is obtained, which is shown in Figure 9. GM-1 is a weak material in terms of its strength properties as compared to POP material. Therefore, the extent of deformation will be more in GM-1 material. From the graph results, it has been analyzed that the deformation in the case of the unlined tunnel is more as compared to lined tunnel samples. Maximum deformation is experienced in the case of a $3 \mathrm{~cm}$ unlined tunnel sample at $\mathrm{L} / 2$ distance, and its value is $0.25 \mathrm{~mm}$, whereas the deformation experienced at $\mathrm{L} / 3$ and $7 \mathrm{~L} / 12$ distance is $0.04 \mathrm{~mm}$ and $0.17 \mathrm{~mm}$, respectively. In the case of $5 \mathrm{~cm}$ cover depth unlined samples, the maximum crown deformation is noticed at $\mathrm{L} / 2$ distance and its value is $0.19 \mathrm{~mm}$, whereas the deformation experienced at $\mathrm{L} / 3$ and $7 \mathrm{~L} / 12$ distance is $0.03 \mathrm{~mm}$ and $0.14 \mathrm{~mm}$, respectively. It is noticed that as the cover depth increases, the deformation decreases. In GM1 tunnel models, the minimum deformation is noticed in the case of $5 \mathrm{~cm}$ lined tunnels.In lined tunnels with a $5 \mathrm{~cm}$ cover depth, the deformation value obtained at $\mathrm{L} / 2$ distance is $0.10 \mathrm{~mm}$, whereas the crown deformation value experienced in $3 \mathrm{~cm}$ lined tunnels is $0.12 \mathrm{~mm}$ at distance $\mathrm{L} / 2$.

Distance along the Tunnel Length $(\mathrm{cm})$

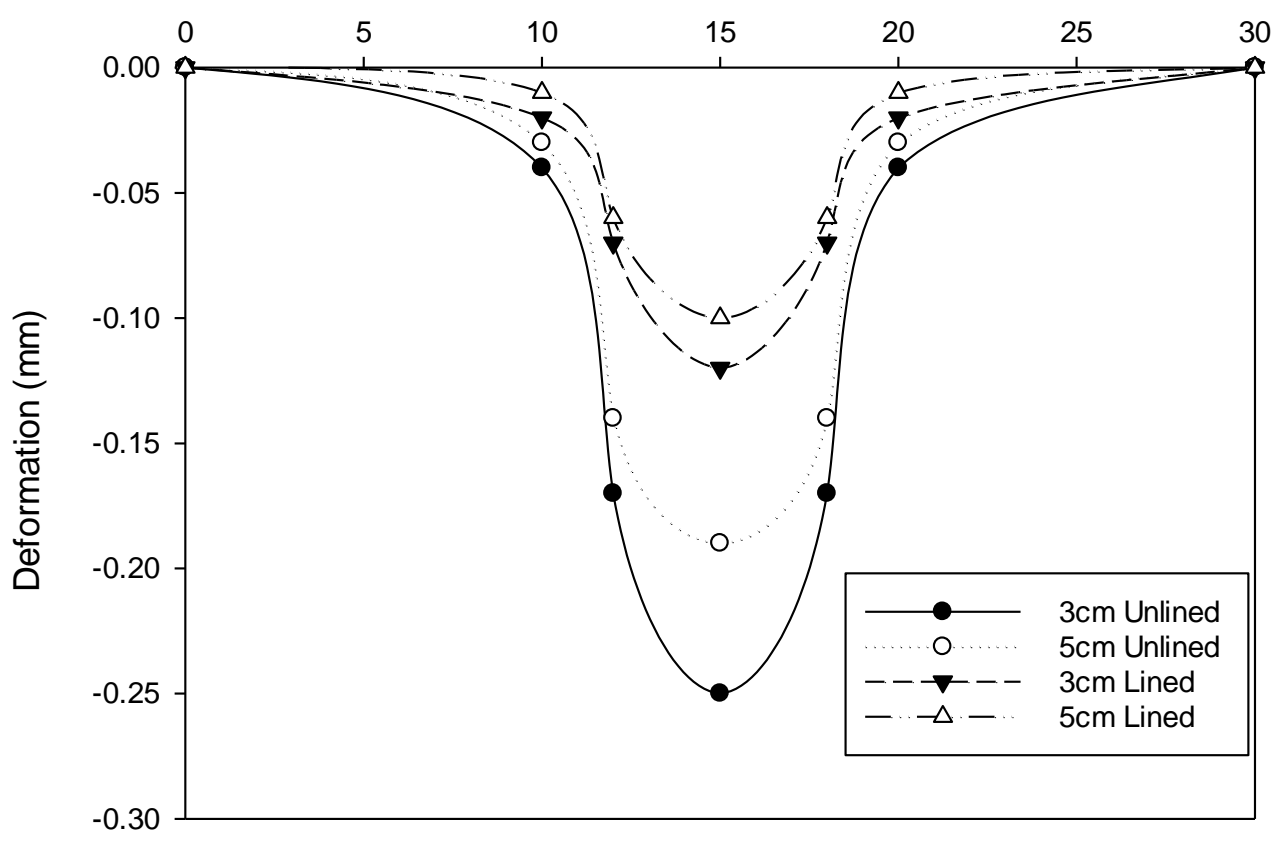

Figure 9. Deformation Profile of Lined and Unlined Tunnel for GM1 material.

After the GM-1 tunnel samples, the rock tunnel prepared from GM-2 (50\% POP, 30\% Sand, and 20\% Clay) material is tested, and the graph is obtained, as shown in Figure 10. When the single tunnels samples of GM-2 material are subjected to static loading conditions, it is observed that in the case of unlined tunnels, maximum deformation occurs at a smaller cover depth. Maximum deformation is experienced in the case of a $3 \mathrm{~cm}$ unlined tunnel. In the $3 \mathrm{~cm}$ unlined tunnel model, the maximum crown deformation of $0.29 \mathrm{~mm}$ is experienced at $\mathrm{L} / 2$ distance, whereas in the case of $5 \mathrm{~cm}$ unlined tunnel models, the maximum crown deformation value is $0.21 \mathrm{~mm}$ at $\mathrm{L} / 2$ distance. In the case of liner material tunnel models, minimum deformation is experienced in the case of $5 \mathrm{~cm}$ lined tunnel samples, and its value is $0.11 \mathrm{~mm}$ at $\mathrm{L} / 2$ distance, whereas in $3 \mathrm{~cm}$ lined material samples, the maximum deformation value is $0.14 \mathrm{~mm}$ at $\mathrm{L} / 2$ distance. 


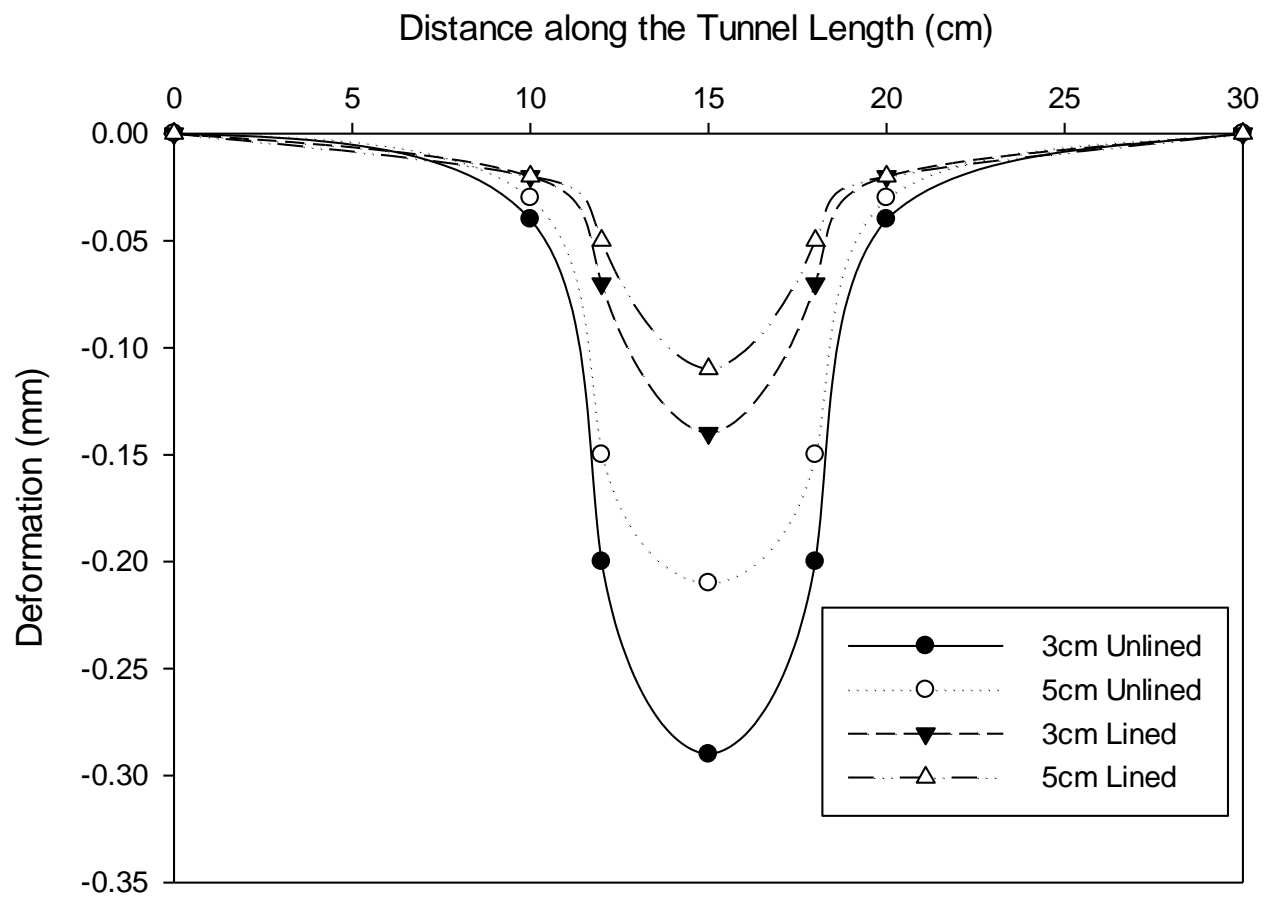

Figure 10. Deformation Profile of Lined and Unlined Tunnel for GM2 material.

After conducting the experimental tests on single tunnels samples of all three model materials, a combined deformation graph is obtained. A comparison of deformation profiles obtained from experimental testing results for single tunnels of different materials is shown in Figure 11. The results show that the maximum deformation occurs in the case of unlined samples of GM-2 model material having a cover depth of $3 \mathrm{~cm}$ and its value is $0.29 \mathrm{~mm}$ at $\mathrm{L} / 2$ distance, i.e., at the centre of the tunnel, whereas the minimum deformation occurs in case of a lined sample of POP model material having a cover depth of $5 \mathrm{~cm}$.

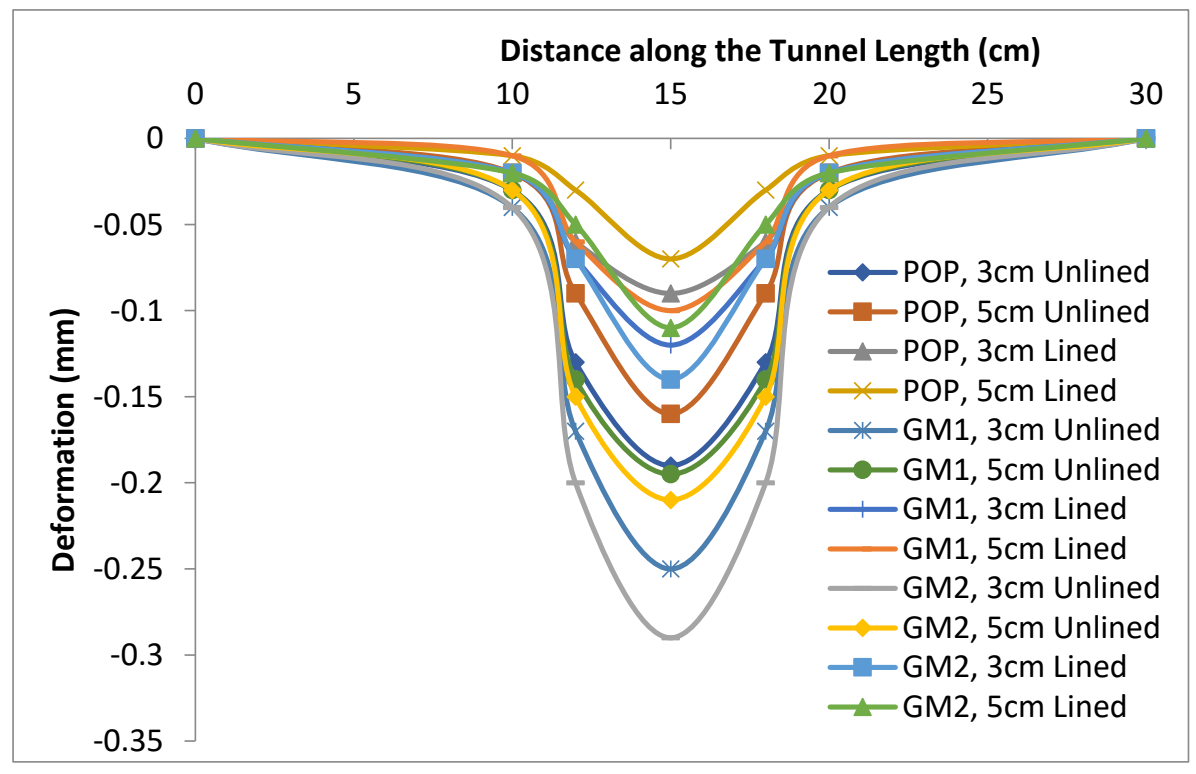

Figure 11. Comparison of deformation profiles for single tunnels of different materials.

From the above results, it has been concluded that the strength properties of rock samples cover depth, and lining material plays an essential role in the deformation of single tunnels. It can also be concluded from the results that maximum deformation is experienced in GM2 material, which is the weakest of all the model materials. In the case 
of $3 \mathrm{~cm}$, cover depth deformation is more as compared to $5 \mathrm{~cm}$. The lowest deformation is experienced in the case of Plaster of Paris model material. In the case of Liner material, less deformation is experienced, which is due to the resistance offered by the liner material.

\subsection{Deformation Behaviour of Twin Tunnel}

In the case of twin tunnel samples, after placing the LVDT in the twin tunnel sample, the sample is then kept in a compression testing machine and is subjected to static loading conditions. Then, the load is applied on the top of the tunnel surface, and deformation occurs in LVDT is recorded in the LVDT data acquisition system. From the deformation, it has been observed that the deformation in both the tunnel at the same positions is identical. Therefore deformation for one tunnel is taken into consideration as the other tunnel has equivalent deformation. From the results, it can also be concluded that maximum deformation is experienced at the centre of the tunnel model, i.e., L/2.The minimum deformation is experienced at the $\mathrm{L} / 3$ distance. The side faces of the tunnel experienced zero deformation. From the deformation pattern, it can be concluded that as the distance increases from the centre of the tunnel, the deformation decreases. It can also be concluded that the maximum deformation is experienced in the case of $1.5 \mathrm{D} \mathrm{c} / \mathrm{c}$ spacing and minimum in $2.5 \mathrm{D} \mathrm{c} / \mathrm{c}$ spacing twin tunnels. From this, it can be concluded that as the spacing between the tunnels increases, there is a decrease in the deformation value. In the case of an unlined tunnel, deformation will be more as compared to a lined sample; this is due to the resistance offered by the liner material.

\subsubsection{Deformation of Lined and Unlined Tunnels Samples Having 1.5D c/c Spacing}

When the twin tunnel sample of $1.5 \mathrm{D} \mathrm{c} / \mathrm{c}$ spacing is subjected to the static loading condition following graph shown in Figure 12 is obtained. Deformation is computed at three different positions along the length of the tunnel. In the case of $3 \mathrm{~cm}$ unlined tunnels, the maximum crown deformation value is $0.25 \mathrm{~mm}$ obtained at $\mathrm{L} / 2$ distance whereas, in the case of $5 \mathrm{~cm}$ unlined samples, the value of maximum crown deformation at $\mathrm{L} / 2$ distance is $0.20 \mathrm{~mm}$. So from the results, it can be concluded that the deformation value is more in unlined tunnels of smaller cover depths, i.e., $3 \mathrm{~cm}$. Also, in lined tunnels, the minimum deformation occurs in $5 \mathrm{~cm}$ lined samples, and its value is 0.10 at $\mathrm{L} / 2$ distance and in $3 \mathrm{~cm}$ lined samples, the maximum crown deformation at $\mathrm{L} / 2$ is $0.12 \mathrm{~mm}$.

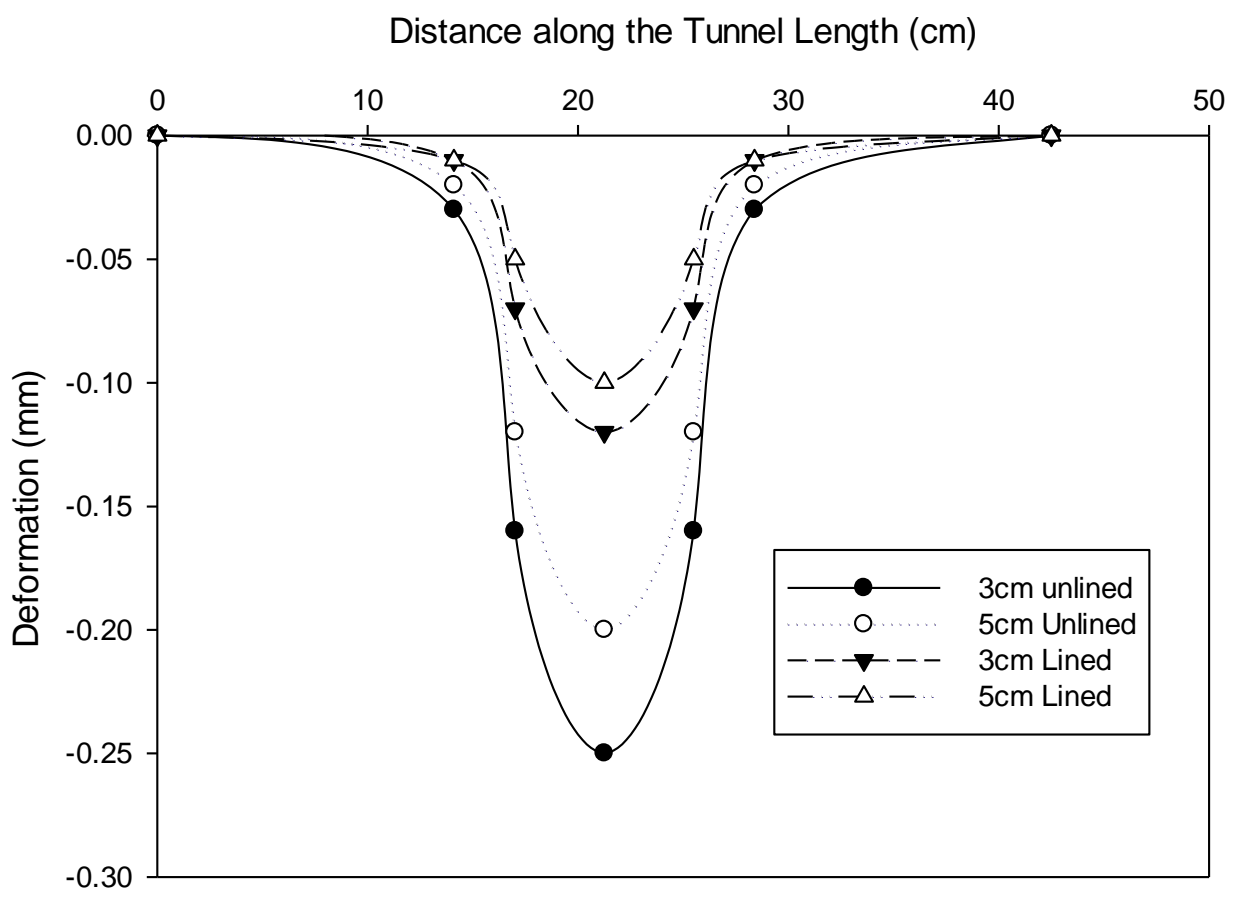

Figure 12. Deformation Profile of Lined and Unlined Tunnel for 1.5D Spacing. 


\subsubsection{Deformation of Lined and Unlined Tunnels Samples Having 2D c/c Spacing}

When the twin tunnel samples having $2 \mathrm{D} \mathrm{c} / \mathrm{c}$ spacing are subjected to loading conditions, the graph obtained is shown in Figure 13. From the graph, it has been concluded that in the case of $2 \mathrm{D} \mathrm{c} / \mathrm{c}$ spacing, deformation is less than as compared to 1.5D. In the case of $2 \mathrm{D} \mathrm{c} / \mathrm{c}$ spacing twin tunnels, the maximum deformation is experienced in the case of a $3 \mathrm{~cm}$ unlined tunnel, and its value is $0.22 \mathrm{~mm}$ at $\mathrm{L} / 2$, whereas the deformation value at $\mathrm{L} / 2$ for $5 \mathrm{~cm}$ unlined sample is $0.18 \mathrm{~mm}$. Minimum deformation occurs in the case of a $5 \mathrm{~cm}$ lined tunnel, and its value is $0.085 \mathrm{~mm}$ at the centre of the tunnel, i.e., $\mathrm{L} / 2$.From the results, it can also be noticed that the maximum deformation occurs at the centre of the tunnel, i.e., $\mathrm{L} / 2$ distance, and minimum deformation occurs at $\mathrm{L} / 3$ distance.

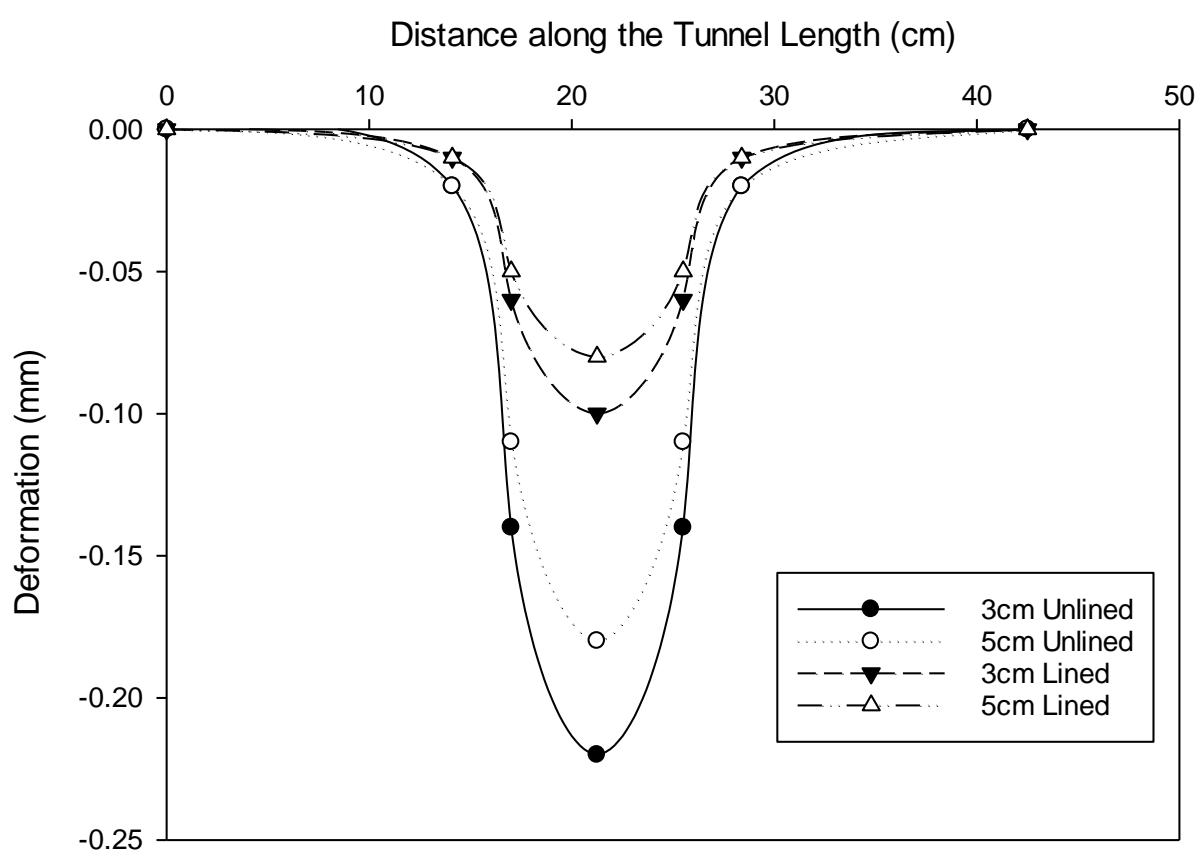

Figure 13. Deformation Profile of Lined and Unlined Tunnel for 2D Spacing.

\subsubsection{Deformation of Lined and Unlined Tunnels Samples Having 2.5D c/c Spacing}

In the case of $2.5 \mathrm{D} c / \mathrm{c}$ spacing, the least deformation is computed. So it can be concluded that in the case of twin tunnel samples, as the distance between the tunnels increases, the deformation decreases. From the results, it can also be concluded that maximum deformation occurs in the case of a $3 \mathrm{~cm}$ unlined tunnel due to the smaller cover depth, and its value is $0.19 \mathrm{~mm}$ at $\mathrm{L} / 2$, whereas the minimum deformation value is noticed in the case of $5 \mathrm{~cm}$ lined samples and its value is $0.08 \mathrm{~mm}$. The deformation profile of lined and unlined Tunnel for 2.5D Spacing is shown in Figure 14.

After conducting the experimental tests on twin tunnels samples of different spacing and cover depth, a combined deformation graph is obtained. A comparison of deformation profiles obtained from experimental testing results for twin tunnels is shown in Figure 15. The results show that the maximum deformation occurs in the case of unlined samples of $1.5 \mathrm{D} \mathrm{c} / \mathrm{c}$ spacing tunnels having a cover depth of $3 \mathrm{~cm}$ and its value is $0.25 \mathrm{~mm}$ at $\mathrm{L} / 2$ distance, whereas the minimum deformation occurs in the case of a lined sample of $2.5 \mathrm{D}$ $\mathrm{c} / \mathrm{c}$ spacing tunnels having a cover depth of $5 \mathrm{~cm}$ and its value is $0.16 \mathrm{~mm}$ at $\mathrm{L} / 2$ distance. 


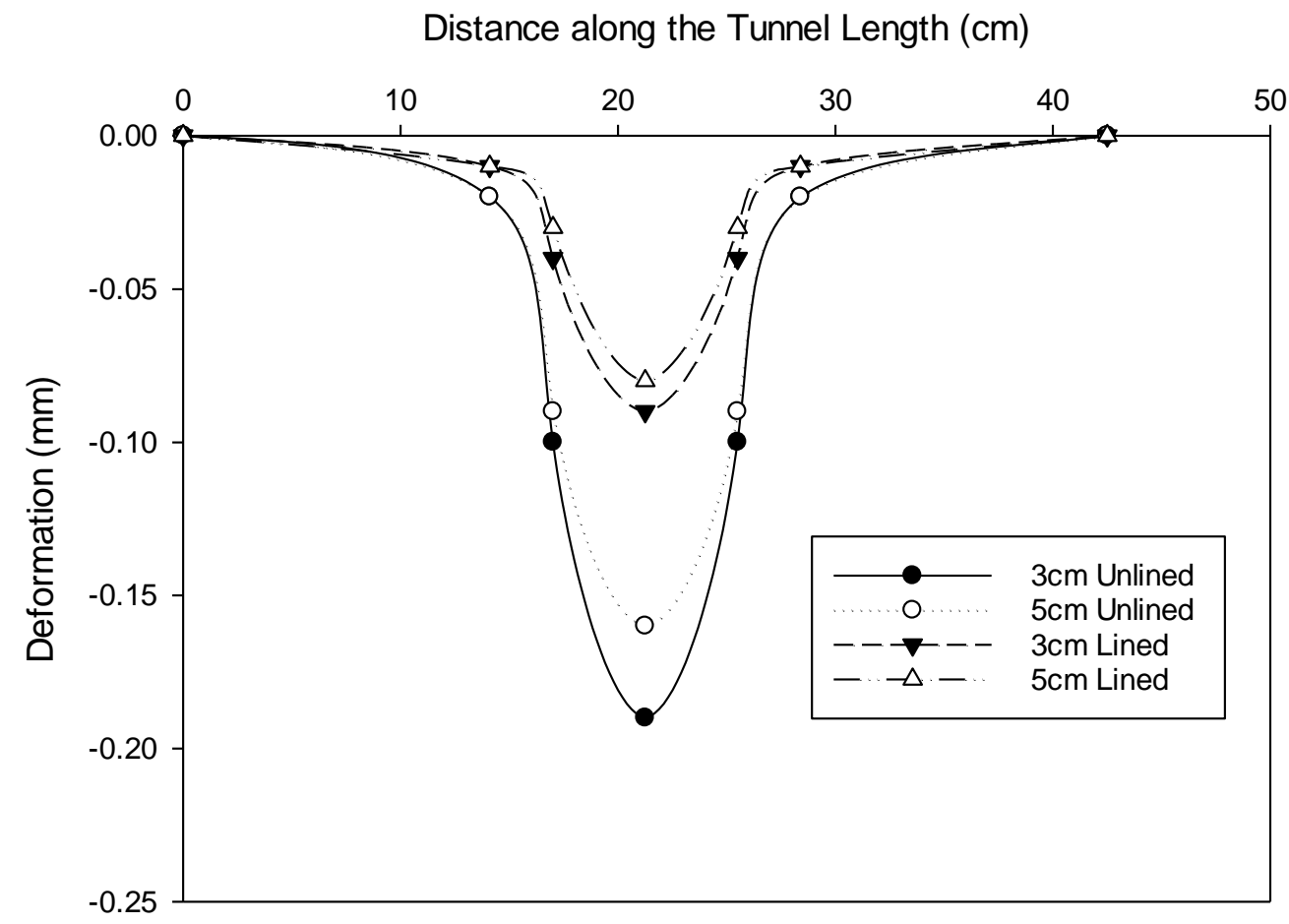

Figure 14. Deformation Profile of Lined and Unlined Tunnel for 2.5D Spacing.

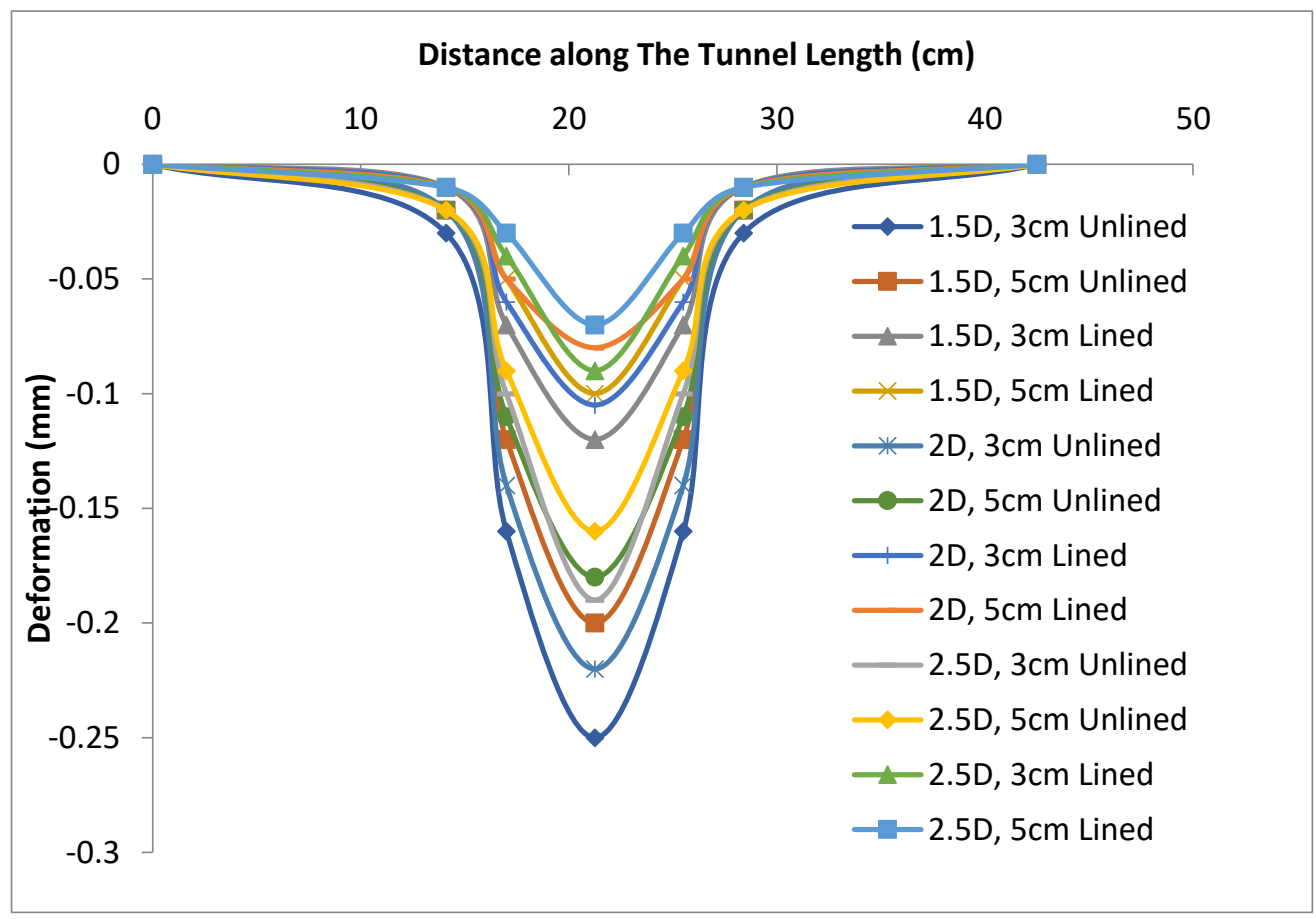

Figure 15. Comparison of deformation profiles for Twin Tunnels of different spacing.

\section{Conclusions}

In the present analysis, an attempt is made to understand the deformation action of single and twin tunnels. The experimental research is performed in a laboratory for this purpose. Three different materials are used in the case of a single tunnel to adjust the strength parameters of the rock. The effect of overburden pressure and liner material on the stability of single tunnels is investigated. Similarly, the effect of a change in cover 
depth and distance between the tunnels is studied in the case of twin tunnels. The following findings can be made from the experimental research conducted on both single and twin tunnels:

(a) In the case of a single tunnel, from the experiment results, it has been observed that the stability of the tunnel depends upon various factors such as the strength of rock, overburden pressure, and liner material.

(b) For the unlined samples of Paster of Paris material, the value of deformation observed at $\mathrm{L} / 2$ distance in $3 \mathrm{~cm}$ cover depth samples is $21.05 \%$ more than the deformation value observed at $\mathrm{L} / 2$ distance in $5 \mathrm{~cm}$ cover depth samples. Similarly, for the unlined samples of GM-1 material, the value of deformation observed at $\mathrm{L} / 2$ distance in $3 \mathrm{~cm}$ cover depth samples is $24 \%$ more than the deformation value observed at $\mathrm{L} / 2$ distance in $5 \mathrm{~cm}$ cover depth samples of GM-1 material, whereas for the unlined samples of GM-2 material, the value of deformation observed at L/2 distance in $3 \mathrm{~cm}$ cover depth samples is $27.58 \%$ more than the deformation value observed at $\mathrm{L} / 2$ distance in $5 \mathrm{~cm}$ cover depth samples of GM-2 material.

(c) For the lined samples of Paster of Paris material, the value of deformation observed at $\mathrm{L} / 2$ distance in $3 \mathrm{~cm}$ cover depth samples is $11 \%$ more than the deformation value observed at $\mathrm{L} / 2$ distance in $5 \mathrm{~cm}$ cover depth samples. Similarly, for the lined samples of GM-1 material, the value of deformation observed at $\mathrm{L} / 2$ distance in $3 \mathrm{~cm}$ cover depth samples is $16 \%$ more than the deformation value observed at $\mathrm{L} / 2$ distance in $5 \mathrm{~cm}$ cover depth samples of GM-1 material, whereas for the lined samples of GM-2 material, the value of deformation observed at $\mathrm{L} / 2$ distance in $3 \mathrm{~cm}$ cover depth samples is $21.42 \%$ more than the deformation value observed at $\mathrm{L} / 2$ distance in $5 \mathrm{~cm}$ cover depth samples of GM-2 material.

(d) It has been observed that in all the cases, the maximum deformation is noted at the centre of the tunnel, i.e., $\mathrm{L} / 2$ distance, and the minimum deformation is recorded at distance $\mathrm{L} / 3$. From the results, it has been concluded that as the distance from the centre increases, the deformation value will decrease. The deformation value is noted as zero at the face of the tunnel in all the cases.

(e) In the case of the twin tunnel samples, from the experimental results, it has been concluded that the value of the deformation observed in $3 \mathrm{~cm}$ unlined tunnels of $1.5 \mathrm{D} \mathrm{c} / \mathrm{c}$ spacing distance is $20 \%$ more than the deformation observed in $5 \mathrm{~cm}$ unlined tunnels of $1.5 \mathrm{D} \mathrm{c} / \mathrm{c}$ spacing distance. At the same time, the value of the deformation observed in $3 \mathrm{~cm}$ unlined tunnels of 2D c/c spacing distance is $18.18 \%$ more than the deformation observed in $5 \mathrm{~cm}$ unlined tunnels of 2D c/c spacing distance. Similarly, the value of the deformation observed in $3 \mathrm{~cm}$ unlined tunnels of $2.5 \mathrm{D} \mathrm{c} / \mathrm{c}$ spacing distance is $15.78 \%$ more than the deformation observed in $5 \mathrm{~cm}$ unlined tunnels of $2 \mathrm{D} \mathrm{c} / \mathrm{c}$ spacing distance.

Author Contributions: P.K. performed and processed the experimental work; P.K., writing—original draft; A.K.S., supervision; P.K., investigation and methodology; A.K.S., review—writing and finalized the final draft for submission and publication. All authors have read and agreed to the published version of the manuscript.

Funding: This research work is funded and supported by Delhi Technological University, Delhi. The authors would like to thank Delhi Technological University for its financial support.

Institutional Review Board Statement: Not applicable.

Informed Consent Statement: Not applicable.

Data Availability Statement: Data sharing is not applicable to this article.

Acknowledgments: The authors would like to thank Delhi Technological University for providing the funding support. Special thanks to the Department of Civil Engineering, the staff of Rock Mechanics Lab for providing remarkable support.

Conflicts of Interest: The authors declare no conflict of interest. 


\section{Abbreviations \\ POP Plaster of Paris \\ PVC Polyvinyl Chloride \\ GM Geo Material \\ $r \quad$ Radial distance \\ a Radius of the tunnel}

\section{References}

1. Bayoumi, A.; Abdallah, M.; Chehade, F.H. Non-Linear Numerical Modeling of the Interaction of Twin Tunnels-Structures. Int. J. Comput. Syst. Eng. 2016, 10, 1059-1063.

2. Chehade, H.F.; Shahrour, I. Numerical analysis of the interaction between twin-tunnels: Influence of the relative position and construction procedure. Tunn. Undergr. Space Technol. 2008, 23, 210-214. [CrossRef]

3. Chen, H.-M.; Yu, H.-S.; Smith, M.J. Physical model tests and numerical simulation for assessing the stability of brick-lined tunnels. Tunn. Undergr. Space Technol. 2016, 53, 109-119. [CrossRef]

4. Chou, W.-I.; Bobet, A. Predictions of ground deformations in shallow tunnels in clay. Tunn. Undergr. Space Technol. 2002, 17, 3-19. [CrossRef]

5. Do, N.A.; Dias, D. A comparison of 2D and 3D numerical simulations of tunnelling in soft soils. Environ. Earth Sci. 2017, 76, 102. [CrossRef]

6. Do, N.A.; Dias, D.; Oreste, P. 3D numerical investigation of mechanized twin tunnels in soft ground-Influence of lagging distance between two tunnel faces. Eng. Struct. 2016, 109, 117-125. [CrossRef]

7. Jin, D.; Yuan, D.; Li, X.; Zheng, H. Analysis of the settlement of an existing tunnel induced by shield tunneling underneath. Tunn. Undergr. Space Technol. 2018, 81, 209-220. [CrossRef]

8. Do, N.A.; Dias, D.; Oreste, P.; Djeran-Maigre, I. 2D numerical investigations of twin tunnel interaction. Geomech. Eng. 2014, 6, 263-275. [CrossRef]

9. Gao, M.-Z.; Zhang, Z.-L.; Qiu, Z.-Q.; Xu, C.; Zhao, J. The mechanism of hysteretic ground settlement caused by shield tunneling in mixed-face conditions. Geomech. Geophys. Geo-Energy Geo-Resour. 2017, 4, 51-61. [CrossRef]

10. Wu, Z.; Zou, S. A static risk assessment model for underwater shield tunnel construction. Sadhana 2020, 45, 1-13. [CrossRef]

11. Elshamy, E.A.; Attia, G.; Fawzy, H.; Hafez, K.A. Behavior of Different Shapes of Twin Tunnels in Soft Clay Soil. Int. J. Eng. Innov. Technol. 2013, 2, 297-302.

12. Fu, J.Y.; Qing, Z.B.; Yu, Y.Z.; Mei, Z.D. Three-dimensional numerical analysis of the interaction of two crossing tunnels in soft clay. Undergr. Space 2019, 4, 310-327.

13. Gao, S.-M.; Chen, J.-P.; Zuo, C.-Q.; Wang, W. Monitoring of Three-dimensional Additional Stress and Strain in Shield Segments of Former Tunnels in the Construction of Closely-Spaced Twin Tunnels. Geotech. Geol. Eng. 2016, 35, 69-81. [CrossRef]

14. Paternesi, A.; Schweiger, H.F.; Scarpelli, G. Numerical analyses of stability and deformation behavior of reinforced and unreinforced tunnel faces. Comput. Geotech. 2017, 88, 256-266. [CrossRef]

15. Qian, H.; Zong, Z.; Wu, C.; Li, J.; Gan, L. Numerical study on the behavior of utility tunnel subjected to ground surface ex-plosion. Thin-Walled Struct. 2021, 161, 107422. [CrossRef]

16. Nunes, M.; Meguid, M. A study on the effects of overlying soil strata on the stresses developing in a tunnel lining. Tunn. Undergr. Space Technol. 2009, 24, 716-722. [CrossRef]

17. Han, H.; Liu, H.; Chan, A.; Mcmanus, T. Three-dimensional finite element modelling of excavation-induced tunnel wall movement and damage: A case study. Sadhana 2019, 44, 185. [CrossRef]

18. Han, Y.; Zhang, L.; Yang, X. Soil-tunnel Interaction under Medium Internal Blast Loading. Procedia Eng. 2016, 143, 403-410. [CrossRef]

19. Jia, P.; Tang, C. Numerical study on failure mechanism of tunnel in jointed rock mass. Tunn. Undergr. Space Technol. 2008, 23, 500-507. [CrossRef]

20. Idris, J.; Verdel, T.; Al-Heib, M. Numerical modelling and mechanical behaviour analysis of ancient tunnel masonry struc-tures. Tunn. Undergr. Space Technol. 2008, 23, 251-263. [CrossRef]

21. Idris, J.; Al-Heib, M.; Verdel, T. Numerical modelling of masonry joints degradation in built tunnels. Tunn. Undergr. Space Technol. 2009, 24, 617-626. [CrossRef]

22. Varma, M.; Maji, V.; Boominathan, A. Numerical modeling of a tunnel in jointed rocks subjected to seismic loading. Undergr. Space 2018, 4, 133-146. [CrossRef]

23. Khan, I.A.; Venkatesh, K.; Srivastava, R.K. Fractured and unfractured analysis of a rock tunnel by finite element method. In Proceedings of the 50th Indian Geotechnical Conference, Pune, India, 17-19 December 2015; pp. 1-12.

24. Lee, T.-H.; Park, D.; Nguyen, D.-D.; Park, J.-S. Damage analysis of cut-and-cover tunnel structures under seismic loading. Bull. Earthq. Eng. 2015, 14, 413-431. [CrossRef]

25. Li, X.; Li, C.; Cao, W.; Tao, M. Dynamic stress concentration and energy evolution of deep-buried tunnels under blasting loads. Int. J. Rock Mech. Min. Sci. 2018, 104, 131-146. [CrossRef] 
26. Rashiddel, A.; Kharghani, M.; Dias, D.; Hajihassani, M. Numerical study of the segmental tunnel lining behavior under a surface explosion-Impact of the longitudinal joints shape. Comput. Geotech. 2020, 128, 103822. [CrossRef]

27. Li, X.; Zhou, Z.; Zhao, F.; Zuo, Y.; Ma, C.; Ye, Z.; Hong, L. Mechanical properties of rock under coupled static-dynamic loads. J. Rock Mech. Geotech. Eng. 2009, 1, 41-47. [CrossRef]

28. Zhang, R.; Xiao, Y.; Zhao, M.; Zhao, H. Stability of dual circular tunnels in a rock mass subjected to surcharge loading. Comput. Geotech. 2019, 108, 257-268. [CrossRef]

29. Li, Y.; Jin, X.; Lv, Z.; Dong, J.; Guo, J. Deformation and mechanical characteristics of tunnel lining in tunnel intersection between subway station tunnel and construction tunnel. Tunn. Undergr. Space Technol. 2016, 56, 22-33. [CrossRef]

30. Li, Z.; Liu, H.; Dai, R.; Su, X. Application of numerical analysis principles and key technology for high fidelity simulation to 3-D physical model tests for underground caverns. Tunn. Undergr. Space Technol. 2005, 20, 390-399. [CrossRef]

31. Liang, R.; Wu, W.; Yu, F.; Jiang, G.; Liu, J. Simplified method for evaluating shield tunnel deformation due to adjacent exca-vation. Tunn. Undergr. Space Technol. 2018, 71, 94-105. [CrossRef]

32. Liang, R.; Xia, T.; Hong, Y.; Yu, F. Effects of above-crossing tunnelling on the existing shield tunnels. Tunn. Undergr. Space Technol. 2016, 58, 159-176. [CrossRef]

33. Liu, X.; Fang, Q.; Zhang, D.; Wang, Z. Behaviour of existing tunnel due to new tunnel construction below. Comput. Geotech. 2019, 110, 71-81. [CrossRef]

34. Mishra, S.; Abhijith, C.; Singh, A.; Kumar, A.; Rao, K.S.; Gupta, N.K. Parametric study of lined and unlined tunnels at shallow depths under coupled static and cyclic loading condition. Tunn. Himal. Geol. 2017, 340, 1-9.

35. Mishra, S.; Rao, K.; Gupta, N.; Kumar, A. Damage to shallow tunnels in different geomaterials under static and dynamic loading. Thin-Walled Struct. 2018, 126, 138-149. [CrossRef]

36. Mishra, S.; Rao, K.; Gupta, N.; Kumar, A. Damage to Shallow Tunnels under Static and Dynamic Loading. Procedia Eng. 2017, 173, 1322-1329. [CrossRef]

37. Moussaei, N.; Sharifzadeh, M.; Sahriar, K.; Khosravi, M.H. A new classification of failure mechanisms at tunnels in stratified rock masses through physical and numerical modeling. Tunn. Undergr. Space Technol. 2019, 91, 103017. [CrossRef]

38. Oliaei, M.; Manafi, E. Static analysis of interaction between twin-tunnels using Discrete Element Method (DEM). Sci. Iran. 2015, 22, 1964-1971.

39. Singh, R.; Singh, T.N.; Bajpai, R.K. The Investigation of Twin Tunnel Stability: Effect of Spacing and Diameter. J. Geol. Soc. India 2018, 91, 563-568. [CrossRef]

40. Nematollahi, M.; Dias, D. Interaction between an underground parking and twin tunnels—Case of the Shiraz subway line. Tunn. Undergr. Space Technol. 2019, 95, 103150. [CrossRef]

41. Shaofeng, L.; Jincai, F.; Pinghua, Z.; Xiang, L. Stability Analysis of Two Parallel Closely Spaced Tunnels Based on Conver-genceConfinement Principle. J. Constr. Eng. Manag. 2018, 144, 04018041. [CrossRef]

42. Qixiang, Y.; Bin, L.; Ping, G.; Cheng, C.; Chuan, H.; Wenbo, Y. Dynamic response of a double-lined shield tunnel to train impact loads. Tunn. Undergr. Space Technol. 2016, 53, 33-45.

43. Sakurai, S. Modeling strategy for jointed rock masses reinforced by rock bolts in tunneling practice. Acta Geotech. 2010, 5, 121-126. [CrossRef]

44. Shalabi, F.I. Interaction of Twin Circular Shallow Tunnels in Soils_Parametric Study. Open J. Civ. Eng. 2017, 07, 100-115. [CrossRef]

45. Wang, Z.; Wong, R.C.; Li, S.; Qiao, L. Finite element analysis of long-term surface settlement above a shallow tunnel in soft ground. Tunn. Undergr. Space Technol. 2012, 30, 85-92. [CrossRef]

46. Zhang, C.; Han, K.; Zhang, D. Face stability analysis of shallow circular tunnels in cohesive-frictional soils. Tunn. Undergr. Space Technol. 2015, 50, 345-357. [CrossRef]

47. Shiau, J.; Al-Asadi, F. Two-dimensional tunnel heading stability factors Fc, Fs and F $\gamma$. Tunn. Undergr. Space Technol. 2020, 97, 103293. [CrossRef]

48. Yang, J.; Yin, Z.-Y.; Liu, X.-F.; Gao, F.-P. Numerical analysis for the role of soil properties to the load transfer in clay foundation due to the traffic load of the metro tunnel. Transp. Geotech. 2020, 23, 100336. [CrossRef]

49. Shirinabadi, R.; Moosavi, E. Twin tunnel behavior under static and dynamic loads of Shiraz metro, Iran. J. Min. Sci. 2016, 52, 461-472. [CrossRef]

50. Shrivastava, A.K.; Rao, K.S. Shear behaviour of non planar rock joints. In Proceedings of the 4th ARC on Soil Mechanics and Geotechnical Engineering, Hong Kong, China, 23-27 May 2011.

51. Shrivastava, A.K.; Rao, K.S. Shear Behaviour of Rock Joints Under CNL and CNS Boundary Conditions. Geotech. Geol. Eng. 2015, 33, 1205-1220. [CrossRef]

52. Shrivastava, A.K.; Rao, K.S. Physical Modeling of Shear Behavior of Infilled Rock Joints Under CNL and CNS Boundary Conditions. Rock Mech. Rock Eng. 2017, 51, 101-118. [CrossRef]

53. Tiwari, R.; Chakraborty, T.; Matsagar, V. Dynamic Analysis of Tunnel in Weathered Rock Subjected to Internal Blast Loading. Rock Mech. Rock Eng. 2016, 49, 4441-4458. [CrossRef]

54. Yingjie, L.; Dingli, Z.; Qian, F.; Qingchun, Y.; Lu, X. A physical and numerical investigation of the failure mechanism of weak rocks surrounding tunnels. Comput. Geotech. 2014, 61, 292-307. 
55. Zhu, Z.; Li, Y.; Xie, J.; Liu, B. The effect of principal stress orientation on tunnel stability. Tunn. Undergr. Space Technol. 2015, 49, 279-286. [CrossRef]

56. Fang, Q.; Tai, Q.; Zhang, D.; Wong, L.N.Y. Ground surface settlements due to construction of closely-spaced twin tunnels with different geometric arrangements. Tunn. Undergr. Space Technol. 2016, 51, 144-151. [CrossRef]

57. Hosseini, N.; Oraee, K.; Gholinejad, M. Seismic Analysis of Horseshoe Tunnels Under Dynamic Loads Due to Earthquake. Undergr. Coal Oper. Conf. 2010, 140-145. 